\title{
OPTOCHIN IN THE IDENTIFICATION OF STR. PNEUMONIAE
}

\author{
BY \\ ERIC F. BOWERS AND LEONARD R. JEFFRIES \\ From University College Hospital, London
}

(RECEIVED FOR PUBLICATION MAY 17, 1954)

In 1911 Morgenroth and Levy showed that mice could be protected against pneumococcal infection with "optochin" (ethylhydrocupreine hydrochloride). The clinical use of this agent was soon abandoned as it was found to be toxic and, in doses which could be tolerated, did not influence the course of lobar pneumonia (Moore and Chesney, 1917 ; White, 1938). Subsequent in vitro studies showed that of the streptococci, Str. pneumoniae was the most sensitive (Moore, 1915), and that as low a concentration as 1 in 50,000 incorporated in blood agar would inhibit growth (Mørch, 1943).

Bile solubility has been generally regarded as the most reliable test for the differentiation of pneumococci from other haemolytic streptococci (Wilson and Miles, 1946). The test, however, is time-consuming and sometimes gives equivocal results.

This paper describes an investigation to determine whether "optochin" sensitivity can be used for the identification of Str. pneumoniae in place of the bile solubility test. A large number of alpha haemolytic streptococci were examined to ascertain the correlation between these tests. Mouse virulence was used as the final criterion of the clinical significance of some of the strains.

\section{Materials and Methods}

Origin of Strains.-Cultures from single colonies of alpha haemolytic Gram-positive cocci were obtained from blood agar cultures of sputa, throat swabs, and pus submitted to this department for routine investigation. A number of strains of Str. pneumoniae were received from other laboratories.

Bile Solubility Test.-About $1 \mathrm{ml}$. of a saline suspension of growth from half a blood agar plate was distributed in two Dreyer tubes to one of which was added 2 drops of a $10 \%$ solution of sodium taurosholate of proved activity and to the other 2 drops of saline. The test was regarded as positive if there was clearing in the taurocholate tube after incubation in the $37^{\circ} \mathrm{C}$. water bath for one and a half hours. Suspensions were consistently of $p \mathrm{H} \mathrm{7.2.}$
Tests which gave incomplete clearing in the taurocholate tube were repeated by both authors and checked by an independent observer.

\section{Optochin Sensitivity}

The Ditch Method.-This method was given in a personal communication from Dr. Landsman.

A ditch about $1 \mathrm{~cm}$. wide was cut across the centre of a blood agar plate and filled with 1 in 50,000 "optochin" in nutrient agar. The test organisms and a known sensitive strain were streaked up to the ditch.

The Disc Method.-Discs of filter paper $8 \mathrm{~mm}$. in diameter were sterilized by dry heat at $160^{\circ} \mathrm{C}$. for one and a half hours. Each disc received $0.02 \mathrm{ml}$. of a 1 in 4,000 solution of "optochin," and was then dried at $37^{\circ} \mathrm{C}$. This concentration of "optochin" gave inhibition zones with Str. pneumoniae slightly smaller than the ditch method. The organisms for test and a known sensitive strain were streaked radially on a blood agar plate, a disc was placed in the centre, and readings were made after overnight incubation at $37^{\circ} \mathrm{C}$.

Similar results were obtained with strips of filter paper $8 \times 1 \mathrm{~cm}$. which had been dipped into the solution, drained of excess fluid, and dried as above. Defibrinated horse blood agar containing $0.005 \%$ para-amino-benzoic acid was used for all experiments. Lysed blood agar without this addition and oxalated blood agar were shown to give similar results.

Ethylhydrocupreine hydrochloride ("optochin," Howards, Ltd., Ilford) is freely soluble in water. The base is insoluble. Solutions of 1 in 500 and 1 in 4,000 have proved stable in the refrigerator and at room temperature. The 1 in 4,000 solution was unaffected by autoclaving at $15 \mathrm{lb}$. for 30 minutes. Sterilization of the discs at $160^{\circ} \mathrm{C}$. cannot be combined with drying of the solution on them, as a considerable loss of potency results. Discs made from 1 in 4,000 solution dried at $37^{\circ} \mathrm{C}$. and stored in screw-capped bottles were stable for nine months in the refrigerator and at room temperature in daylight.

Mouse Virulence Test.-Mice were inoculated intraperitoneally with $0.5 \mathrm{ml}$. of an overnight serum broth culture. Deaths within seven days were recorded. 
From dead animals, cultures of the heart blood were made, and stained smears of heart blood and peritoneal exudate examined for the presence of Str. pneumoniae.

\section{Experimental}

Complete insensitivity to " optochin" was shown by growth of organisms right up to the edge of the disc or ditch. Sensitivity was of two grades, which could be very easily distinguished. Full sensitivity resulted in a zone of inhibition of more than $5 \mathrm{~mm}$. from the edge of the disc. Partially sensitive strains gave very small zones not exceeding $2 \mathrm{~mm}$.

TABLE I

\begin{tabular}{|c|c|c|c|c|c|}
\hline \multirow{2}{*}{\multicolumn{2}{|c|}{ Strain }} & \multirow{2}{*}{$\begin{array}{l}\text { No. of } \\
\text { Strains }\end{array}$} & \multicolumn{3}{|c|}{$\begin{array}{c}\text { Inhibition from Edge of Optochin } \\
\text { Disc in mm. } \\
\end{array}$} \\
\hline & & & Nil & 1 or 2 & 5 to 9 \\
\hline $\begin{array}{l}\text { Bile soluble } \\
\text { ", insoluble }\end{array}$ & $\because$. & 243 & $\begin{array}{l}\text { None } \\
434\end{array}$ & 17 & $\begin{array}{r}242 \\
1\end{array}$ \\
\hline
\end{tabular}

Table I records the "optochin" sensitivities of 243 bile-soluble strains and 452 bile-insoluble strains. Of the former, all except one were fully sensitive to "optochin"; the exception was partially sensitive and was found to be completely avirulent for the mouse. Of the bile-insoluble strains, only one was fully "optochin" sensitive, but 17 were partially so. The wholly sensitive strain and 13 of the 17 partially sensitive strains were tested for mouse virulence and all were found to be completely avirulent.

There is thus almost complete correlation between bile solubility and full "optochin" sensitivity, but $2.4 \%$ of the 695 strains examined showed slight "optochin" sensitivity in spite of being bile insoluble. As all of these which were tested were found to be completely avirulent for mice it is reasonable to assume, either that they were not true pneumococci, or that they represented completely rough variants unlikely to be of any clinical significance.

The proportion of bile-insoluble streptococci giving visible evidence of slight sensitivity to "optochin" can be reduced by reducing the concentration of " optochin" used. This, however, is accompanied by a reduction in the size of the zone of inhibition given by true pneumococci. The relation between "optochin" concentration and zone size was determined by tests on 55 strains of Str. pneumoniae by the disc method, with various concentrations of " optochin." The results are tabulated in Table II.

As inhibition zones of $2 \mathrm{~mm}$. might be missed by inexperienced observers it would be unwise to
1 ABLE II

\begin{tabular}{l|c}
\hline Optochin & $\begin{array}{c}\text { Limits of Zones of Inhibition of } \\
\text { Str. pneumoniae }(\mathrm{mm} .)\end{array}$ \\
\hline $1 / 4,000$ & 5 to 9 \\
$1 / 8,000$ & $4 \% 8$ \\
$1 / 16,000$ & $2 \% 6$ \\
\hline
\end{tabular}

use an "optochin" concentration of less than 1 in 8,000 for routine diagnostic work. In practice, we have found that a concentration of 1 in 4,000 is satisfactory and does not give rise to any difficulty in distinguishing between the inhibition zones of pneumococci and of the anomalous strains of bile-insoluble streptococci. As an additional check we also record the size of the inhibition zone of a control Str. pneumoniae for each disc. The sensitivity of this control strain has not altered with daily subculture on blood agar for one year.

\section{Experimental Dissociation of Bile Solubility and Optochin Sensitivity}

In view of the natural occurrence of strains showing no correlation between "optochin" sensitivity and bile solubility an attempt was made to separate these characteristics experimentally.

Str. pneumoniae type I (N.C.T.C. 7465) was shown to be bile soluble, "optochin" sensitive, and mouse virulent. A series of dilutions of "optochin" in 5\% serum broth was seeded from an overnight serum broth culture of this organism. After 24 hours' incubation the culture containing the highest concentration of "optochin" and showing turbidity was used to inoculate a second series of "optochin" serum broths. This procedure was repeated through a number of serial subcultures.

After two subcultures the organism became "optochin" resistant. In the standard disc test it grew up to the disc, and its sensitivity, tested by titration in serum broth, had decreased from 1 in 500,000 to 1 in 50,000 . It was bile soluble.

After eight subcultures "optochin" sensitivity had fallen to 1 in 5,000 , though the organism still remained bile soluble. At this stage the mouse virulence test was repeated. To exclude the possibility of a bacteriostatic effect from the presence of traces of "optochin," the pneumococci were washed in peptone water and resuspended before injection. Furthermore the test was repeated after three serial subcultures in serum broth to eliminate "optochin" which may have been adsorbed on the cells. In each test the mice survived, indicating an association between loss of "optochin" sensitivity and loss of mouse virulence, with dissociation from the bile solubility. 
A second attempt to separate the properties of bile solubility and "optochin" sensitivity of the original strain (N.C.T.C. 7465 ) was made by serial culture in $10 \%$ type specific antiserum in serum broth. Through 14 daily subcultures the organism remained bile soluble and "optochin" sensitive, though losing mouse virulence.

\section{Application}

The colonial morphology of some strains of Str. pneumoniae and Str. viridans is very similar. When two such strains appear in a mixed culture either may go unrecognized and the proportion of each may be difficult to assess. In a routine diagnostic laboratory it is not always practicable to avoid this error by testing numerous colonies from each plate. An alternative simple method is to place an "optochin" disc on the pool of inoculum of the original blood agar plate. The presence of large numbers of pneumococci will be revealed by a zone of sparser growth round the disc due to inhibition of the pneumococci. The effect-is striking even when fairly heavy growth of other organisms, including Str. viridans, occurs right up to the edge of the disc. Plates incubated anaerobically show the effect even more clearly, because many bacterial species are inhibited under these conditions. Nor does the addition of $10 \%$ carbon dioxide to the atmosphere affect the phenomenon. A confirmatory Gram-stained film should be ex- amined before making a report. Alternatively several single colonies may be tested by the " optochin" disc or strip on one blood agar plate.

\section{Summary}

"Optochin" sensitivity offers a satisfactory means of identification of Str. pneumoniae. It is less time-consuming than the bile solubility test,

Of 695 strains of alpha haemolytic streptococci tested, only two showed lack of correlation between bile solubility and full "optochin" sensitivity.

The "optochin" disc method facilitates detection of Str. pneumoniae on overnight plate cultures of sputum or pus containing a mixed bacterial flora.

One strain of pneumococcus was experimentally rendered "optochin" insensitive while retaining its bile solubility.

We wish to thank Professor Wilson Smith, F.R.S., and Dr. E. J. Stokes for their guidance and encouragement in the preparation of this paper. We are grateful to those who have sent us strains of Str. pneumoniae, especially Mr. E. Y. Bridson.

\section{REFERENCES}

Mørch, Erna (1943). Serological Studies on the Pneumococci. Munksgaard, Copenhagen; Oxford University Press, London. Moore, H. F. (1915). J. exp. Med., 22, 269.

and Chesney, A. M. (1917). Arch. intern. Med., 19, 611.

Morgenroth J and Levy, R. (1911). Berl. klin. Wschr., 48, 1560 White, B. (1938). The Biology of Pneumococcus. Commonwealth Fund, New York.

Wilson, G. S. Topley and Wilson's Principles of Bacteriology and Immunity, 3rd ed. Arnold, London. 